\title{
Traumatic stress as a mediator of quality of life and burden in informal caregivers of amputees due to diabetic foot: a longitudinal study
}

\begin{abstract}
BACKGROUND
Type 2 diabetes mellitus (DMT2) is frequently associated with complications that can lead to lower limb amputation, being the second major cause of amputation. The amputee becomes dependent on caregivers, who are often unprepared for this new role and face many challenges. Caregiving influences several dimensions of the caregiver's life. This study evaluates the mediating role of traumatic stress in the relationship between caregiver perceived stress and burden/quality of life (QoL) taking also into consideration the duration of caregiving and whether the caregiver receives help in caregiving tasks, in informal caregivers of amputees due to diabetic foot over a 10 month period.
\end{abstract}

\section{PARTICIPANTS AND PROCEDURE}

The sample consisted of 110 informal caregivers of amputees due to diabetic foot with type 2 diabetes. This longitudinal study evaluates, at three time points, the mediating role of traumatic stress in the relationship between perceived stress and burden/quality of life considering the duration of caregiving and whether the caregiver received help and social support in caregiving tasks.

\section{RESULTS}

The results showed that the duration of caregiving, help in caregiving and caregiver stress (T1) predicted traumatic stress seven months (T2) after patients' amputation; and traumatic stress (T2) predicted mental QoL and burden, 10 months later (T3).

\section{CONCLUSIONS}

This study emphasizes the importance of intervention in caregivers at the beginning of caregiving, to improve mental QoL and decrease the burden, ten months after amputation.

\section{KEY WORDS}

burden; caregiver stress; caregivers; quality of life; traumatic stress

ORganization - School of Psychology, University of Minho, Braga, Portugal

AUthors' Contributions - A: Study design - B: Data collection - C: Statistical analysis - D: Data interpretation .

E: Manuscript preparation · F: Literature search · G: Funds collection

CORRESPONDIng AUthor - Prof. M. Graça Pereira, School of Psychology, University of Minho, Campus de Gualtar, 4710-057 Braga, Portugal, e-mail: gracep@psi.uminho.pt

to CITE this ARTICLE - Costa, S., Ferreira, J., Leite, Â., \& Pereira, M. G. (2021). Traumatic stress as a mediator of quality

of life and burden in informal caregivers of amputees due to diabetic foot: a longitudinal study. Health Psychology

Report, 9(4), 338-348. https://doi.org/10.5114/hpr.2020.101495

RECEIVED 26.06.2020 • REVIEWED 21.08.2020 • ACCEPTED 07.10.2020 • PUBLISHED 07.12.2020 


\section{BACKGROUND}

Type 2 diabetes mellitus (DMT2) is frequently associated with complications that can lead to lower limb amputation, being the second major cause of amputation (Nazarko, 2019). The amputee becomes dependent on caregivers, who are often unprepared for this new role because, in most cases, they are called to this role unexpectedly. Additionally, after the amputation surgery, patients face enormous physical, emotional, social and occupational challenges, which compromise their functionality (Day et al., 2019).

Caregiving influences several dimensions of the caregiver's life, such as physical (e.g., physical health deterioration), psychological (e.g., anxiety and traumatic stress), family (e.g., roles and routines) and social (e.g., leisure time and social life) (Ganjparvar et al., 2016). Caregivers under stress, due to the caregiving role, report high levels of depressive symptoms, anxiety, high use of psychotropic drugs, low satisfaction with life, several symptoms related to psychological stress, and low subjective health (Da Silva et al., 2013). Consequently, informal caregivers show high levels of burden that may lead to a decrease in their quality of life (QoL) with an impact on physical and mental health (Bevans \& Sternberg, 2012; Ganjparvar et al., 2016; Valeberg \& Grov, 2013). Caregiver burden has a mental and physical impact and is associated with less leisure time, stress and health problems; sometimes, caregivers give up work or study due to caregiving (Tochel et al., 2019). Caregiver quality of life is affected by changes in lifestyle, freedom, physical burden, and emotional disturbance that impact life as a whole (Tochel et al., 2019). However, caregiver burden has been ranked by the caregivers as an outcome with low priority (Barrios et al., 2016).

The literature has revealed that caring for a lowerlimb diabetic amputee compromises the caregiver's QoL (Bandeira \& Barroso, 2005; Foss et al., 2009; Kaux et al., 2016; Kang et al., 2019). More specifically, a qualitative study by Franchini and Savoia (2018) showed that caregivers of lower-limb amputees due to DMT2 focused exclusively on the patient's disease and treatment, without boundaries between their own and the patient's life. This stressful context may lead to post-traumatic stress disorder (PTSD) (Mason et al., 2019).

In the caring process, the disease is both a threat and a challenge for the caregiver (Ryu et al., 2016) that may change the course of daily life and result in angry feelings and an inability to control the course of events. However, the literature has shown that not all the caregivers develop PTSD (Vranceanu, 2019), or experience tension (Burgio et al., 2016) due to the caring process. Also, Wintermann and colleagues (2019) found that post-traumatic stress symptoms impact on health-related quality of life in a cohort study with chronically critically ill patients; and Young-Hyman et al. (2016) found that post-traumatic stress symptoms had an impact on burden in patients with diabetes.

Golden-Kreutz et al. (2005) studied the relationship between stress, at initial cancer diagnosis and treatment, and subsequent QoL and found that stress predicted both psychological and physical QoL at the follow-up. Pedras et al. (2019), in a longitudinal study with a sample of patients who had undergone a lower limb amputation, found that traumatic stress symptoms were prevalent one month after amputation and decreased six and ten months after amputation surgery, in patients. Also, Pedras et al. (2018) found in amputated patients that traumatic stress symptoms were negatively associated with general and social adjustment, and adjustment to the limitations. However, in caregivers of amputated patients, there are few studies addressing the role of traumatic stress.

The multifactorial PTSD outcome model of Boscarino (2004) presented different causal pathways to disease, showing the associations between trauma exposure, PTSD, and health outcomes. In this model, PTSD and trauma exposure mediated the relationship between biophysiological processes and health status through behavior perceptions (Boscarino, 2004). In addition, research has identified that social support is a good predictor of health and well-being, regarding caregivers. Lage (2005) considers that social support received by caregivers is a protective factor that decreases the negative consequences of caring, buffering the effect of stress on health (Pan et al., 2019). Besides protecting individuals from PTSD onset, social support also influences effective PTSD treatment (Boscarino, 2000).

Family caregivers of patients with a disability report burden and stress due to caregiving (Chang et al., 2010). Caregivers who receive help report lower levels of burden and those who do not receive help show higher levels of burden and stress, over time, compared with the initial baseline (Costa et al., 2018). In fact, perceived social support was shown to mediate the relationship between traumatic stress symptoms and adjustment to the limitations (Pedras et al., 2018).

There are few longitudinal studies on the mediating role of traumatic stress in caregivers of lowerlimb amputees due to diabetic foot (Pedras et al., 2016, 2018). Consequently, it is vital to determine whether traumatic stress mediates the relationship between caregiver perceived stress (physiological process)/social support and burden/QoL taking also into consideration the duration of caregiving and whether the caregiver received help in caregiving tasks. Given that DMT2 is frequently associated with complications that can lead to lower limb amputation, which negatively affects patients as well as caregivers, and
Informal caregivers of amputees due to diabetic foot 
Suelly Costa,

Joana Ferreira,

Ângela Leite,

M. Graça Pereira that traumatic stress has a negative impact on caregiver burden (Ganjparvar et al., 2016) with implications for the patient's QoL, from a heuristic point of view, it is fundamental to assess whether traumatic stress mediates the relationship between caregiver stress and burden/QoL, taking also into consideration the caregiver's help and duration of caregiving. Understanding both the physiological (stress) and the psychological aspects of traumatic stress is warranted in caregivers so that intervention programs can be designed to decrease traumatic stress in this population.

Based on the Boscarino model (2004) and the literature (Golden-Kreutz et al., 2005; Pedras et al., 2019), the present study is focused on the following hypotheses: (1) caregiver stress, social support, help in caregiving and duration of caregiving at T1 predict post-traumatic stress at T2, which, in turn, will predict burden and QoL at T3; (2) traumatic stress mediates the relationship between caregiver stress, social support, help in caregiving and duration of caregiving (T1), and burden/QoL (T3).

\section{PARTICIPANTS AND PROCEDURE}

\section{PARTICIPANTS}

The sample consisted of 110 informal caregivers of amputees due to diabetic foot with type 2 diabetes. The inclusion criteria at T1 were: being over 18 years old, and a caregiver of a patient with diabetes type 2 with consequent amputation in the month prior to the evaluation.

The protocol for the research project was approved by Ethical Committees of the six hospitals where the study took place. All procedures of this study are in accordance with the World Medical Association Declaration of Helsinki in 1995 (as revised in Brasil 2013) and conform to the ICMJE Recommendations for the Conduct, Reporting, Editing, and Publication of Scholarly Work in Medical Journals. Caregivers' participation was voluntary and confidential, and data collection followed all ethical and deontological assumptions. All caregivers provided written consent and their anonymity was preserved. This study followed a longitudinal quantitative design with three time points: one month (T1), seven months (T2), and ten months (T3) after the patient's amputation surgery. The timing of the assessment was set considering patients' clinical criteria in diabetic foot consultations and outpatient vascular surgery.

\section{MEASURES}

Patients were evaluated with a Sociodemographic and Clinical Questionnaire, the Social Support Sat- isfaction Scale (SSSS), the Self-Assessment Caregiver Questionnaire, the Revised Impact of Events Scale (IES-R), the Burden Assessment Scale (BAS), and the Short Form Health Survey (SF36).

Sociodemographic and Clinical Questionnaire. The sociodemographic and clinical questionnaire consisted of questions related to caregivers' sociodemographic variables (age, gender, marital status, education and professional status) and clinical variables associated with caregiving (degree of kinship, help with the care and beginning of care).

Social Support Satisfaction Scale (SSSS; Ribeiro, 1999). The Social Support Satisfaction Scale assesses satisfaction with social support through 15 items grouped into the following subscales: satisfaction with friends, satisfaction with intimacy, satisfaction with family and satisfaction with social activities. High scores indicate a higher perception of satisfaction with social support. In the original version, Cronbach's $\alpha$ for the total scale was .85 (Ribeiro, 1999) and in this study .86.

Self-Assessment Caregiver Questionnaire (CSAQ; Epstein et al., 1983; Portuguese version by Pereira \& Costa, 2013b). The Self-Assessment Caregiver Questionnaire is a self-report instrument that assesses caregiver stress (Epstein-Lubow et al., 2010). The questionnaire consists of 16 items scored in two positive and negative dimensions of caregivers' reactions $(1-y e s$ and $0-n o)$, plus two specific items for stress levels (item 17) and health (item 18), scored between 1 and 10. A total score is obtained by adding the 16 items. High scores indicate that caregivers present high levels of stress symptoms due to caregiving. Two specific items (17 and 18) are scored with an algorithm that leads to three acuity ranges (low, moderate, or high) in a scale from 1 to 10 , in which scores above six are considered high (Epstein-Lubow et al., 2010). In the original version, the Cronbach $\alpha$ was .78 and in the Portuguese version and in this study it was .83 for the total scale.

Revised Impact of Events Scale (IES-R; Weiss \& Marmar, 1997; Portuguese version by Pereira \& Costa, 2013a). The Revised Impact of Events Scale assesses the presence of traumatic symptomology through 22 items scored on a five-point Likert scale from 0 (not at all), 1 (a little bit), 2 (moderately), 3 (quite a bit) to 4 (extremely), grouped in three subscales: intrusion (8 items), avoidance (8 items) and hyperarousal (6 items). A high total score indicates higher psychological, behavioral, and cognitive difficulties due to exposure to trauma (Weiss \& Marmar, 1997). The original and the Portuguese versions showed Cronbach $\alpha$ of .93 and .96 respectively. In this sample, the Cronbach $\alpha$ for the total scale was .96 .

Burden Assessment Scale (BAS; Reinhard et al., 1994; Portuguese version by Coutrim et al., 2007). The Burden Assessment Scale evaluates family exhaustion, that is, the demands felt by caring for someone 
with limitations in activities and resources. The scale consists of 19 items and three subscales (disrupted activities; personal distress; and time perspective). Scores for the total scale are calculated by adding the three subscales, where high scores are associated with high levels of burden. In the original version, the Cronbach $\alpha$ was .89 for the total scale and, in the present study it was .88 .

Short Form Health Survey (SF36; Ware et al., 1998; Portuguese version by Ferreira, 2000). The Short Form Health Survey assesses QoL in the physical and mental dimension. It consists of 11 items and 36 questions that evaluate 8 components: physical functioning, physical role functioning, emotional role functioning, bodily pain, vitality, social role functioning, mental health, and general health perceptions. A high score in each dimension indicates better physical or mental QoL. In the Portuguese version, the Cronbach $\alpha$ for the physical dimension was .92 and .91 for the mental dimension, whereas in the present study it was .92 and .89 for the physical and mental dimensions, respectively.

\section{STATISTICAL ANALYSIS}

Statistical analyses were performed with the SPSS software (IBM SPSS version 25). Descriptive statistics were used to describe the sociodemographic and clinical characteristics of the sample. To test the relationships between the sociodemographic, clinical and psychological variables, the Pearson correlation coefficient was used since the variables presented a normal distribution. ANOVA for repeated measures was used to compare psychological variables over time. Finally, to assess which variables at T1 predicted QoL/burden at T3, a path analysis was performed using AMOS (version 25) for SPSS.

\section{RESULTS}

\section{DESCRIPTIVE STATISTICS}

The sample consisted of 110 caregivers (at T1); at $\mathrm{T} 2$, the number of caregivers decreased to 101 and at T3 to 84. Caregivers' age ranged between 19 and 82 years old $(M=51.60, S D=15.32)$ and they were mainly women (85.5\%), with six or less years of education $(73.7 \%)$, unemployed or retired $(66.4 \%)$, and married or living in cohabitation (80.9\%). Most of the participants take care of a husband/wife $(46.4 \%)$ or of an offspring (34.5\%), do not have help in caregiving $(50.9 \%)$, had begun to provide care before the patient's amputation (73.6\%) and had been a caregiver for an average of 69.28 months.

\section{PSYCHOLOGICAL VARIABLES AT T1, T2 AND T3}

None of the psychological variables changed significantly over the three assessment moments, except burden, which significantly decreased from T1 to T2 and T3 (Table 1).

\section{RELATIONSHIPS BETWEEN \\ SOCIODEMOGRAPHIC, CLINICAL, PSYCHOLOGICAL VARIABLES AND QOL/BURDEN}

Social support, caregiver stress and traumatic stress at T1 correlated negatively with traumatic stress at T2. Also, caregiver stress at T1 was negatively associated with mental QoL at T3. Caregiver's age correlated negatively with physical QoL at T3 and caregiver's education correlated positively with physical QoL at T3.
Informal caregivers of amputees due to diabetic foot

\section{Table 1}

Descriptive statistics for psychological variables at the three evaluation times

\begin{tabular}{lccccc}
\hline Psychological variables & Min-Max & $\begin{array}{c}\mathrm{T} 1(n=110) \\
M(S D)\end{array}$ & $\begin{array}{c}\mathrm{T} 2(n=101) \\
M(S D)\end{array}$ & $\begin{array}{c}\mathrm{T} 3(n=74) \\
M(S D)\end{array}$ & $F(2,146)$ \\
\hline $\begin{array}{l}\text { Social support } \\
\text { Caregiving stress }\end{array}$ & $15-75$ & $53.77(10.35)$ & $52.13(13.00)$ & $54.10(12.67)$ & 0.16 \\
Mediator variable & $2-14$ & $7.96(5.93)$ & $6.06(4.22)$ & $5.96(4.43)$ & 2.87 \\
$\begin{array}{l}\text { Traumatic stress } \\
\text { Outcome variables }\end{array}$ & $0-84$ & $16.55(16.22)$ & $14.09(15.58)$ & $10.41(12.42)$ & 3.01 \\
$\begin{array}{l}\text { Physical QoL } \\
\text { Mental QoL }\end{array}$ & $21-87$ & $72.12(12.50)$ & $70.53(13.01)$ & $73.10(12.12)$ & 0.72 \\
Burden & $14-70$ & $50.40(10.63)$ & $50.29(10.78)$ & $50.21(11.58)$ & 0.65 \\
\hline
\end{tabular}

Note. F-ANOVA for repeated measures; ${ }^{* *} p<.001$. 
Suelly Costa,

Joana Ferreira

Ângela Leite, M. Graça Pereira

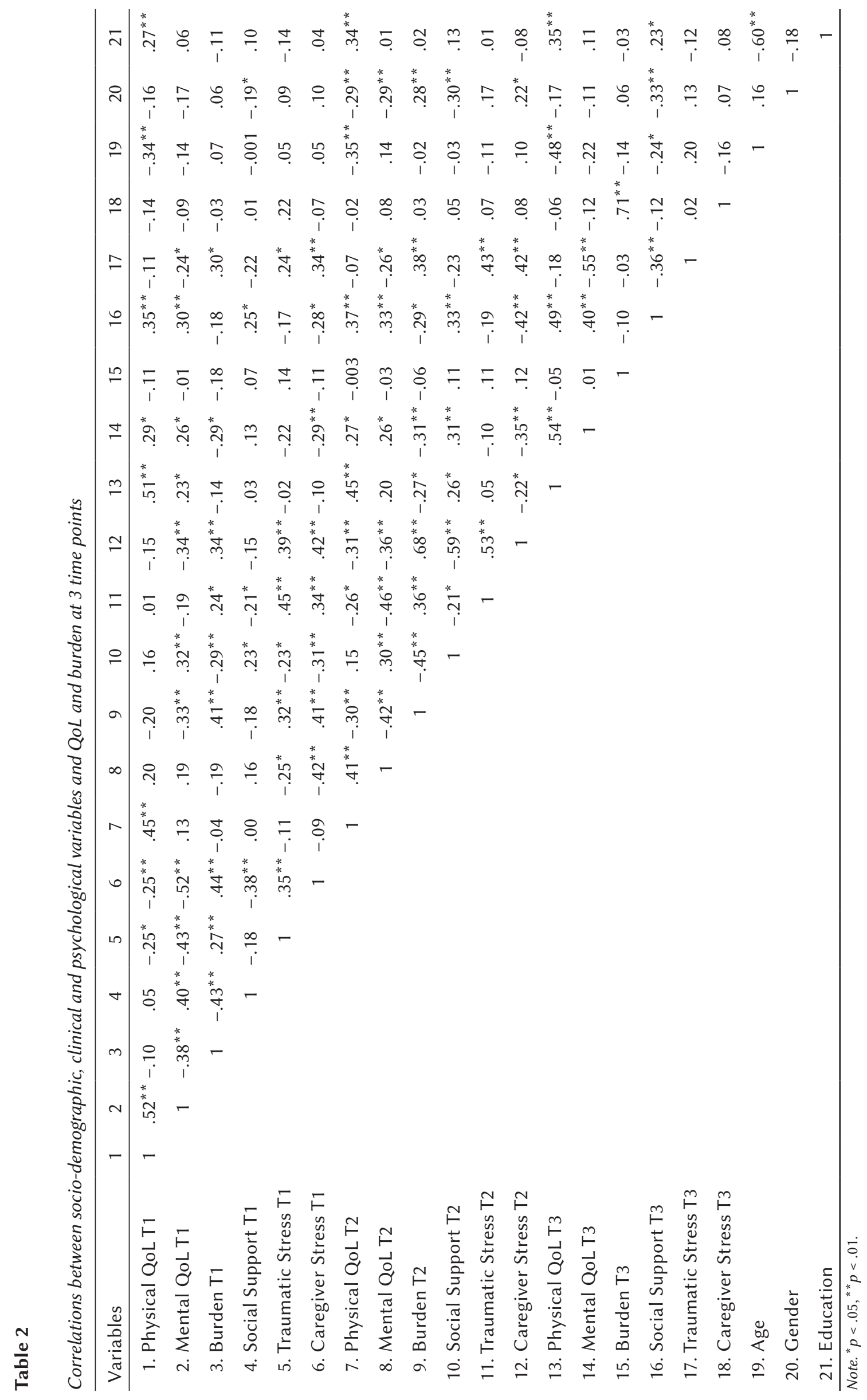


Social support at T2 correlated negatively with traumatic stress at T2 and positively with physical QoL at T3. Caregiver stress at T2 correlated positively with traumatic stress at $\mathrm{T} 2$ and negatively with physical and mental QoL at T3.

\section{RELATIONSHIPS BETWEEN VARIABLES:} PATH ANALYSIS

The path analysis provided two types of results: estimates of the model fit to data and estimates of the relationship strength between the variables in the model. Results of the final model showed a good model fit: $\chi^{2}=10.45, d f=11$, TLI $=1.385, \mathrm{CFI}=1.000$, RMSEA $=.000$. Duration of caregiving $(\beta=-.13)$, help in caregiving $(\beta=-.11)$, and caregiver stress $(\beta=.36)$ at $\mathrm{T} 1$ predicted traumatic stress seven months af- ter patients' amputation (T2) and the latter predicted mental QoL $(\beta=-.11)$ and burden $(\beta=.12)$ at 10 months (T3).

Figure 1 shows the initial model and Figure 2 the final model that resulted from the path analysis. Table 3 shows the standardized indirect effects.

\section{DISCUSSION}

Age correlated negatively with physical QoL at T3, in accordance with Wintermann and colleagues (2019), who revealed the importance of age in the impact of post-traumatic stress symptoms on healthrelated quality of life in a cohort study with chronic patients and their partners. Also, education correlated positively with physical QoL in accordance with Schnitzer and colleagues (2017), who found that bet-

\section{Figure 1}

Initial model: $\chi^{2}=483.86, d f=23, T L I=-13.769, C F I=.000, R M S E A=.304$



\section{Figure 2}

Final model: $\chi^{2}=10.45, d f=11, T L I=1.385, C F I=1.000, R M S E A=.000$

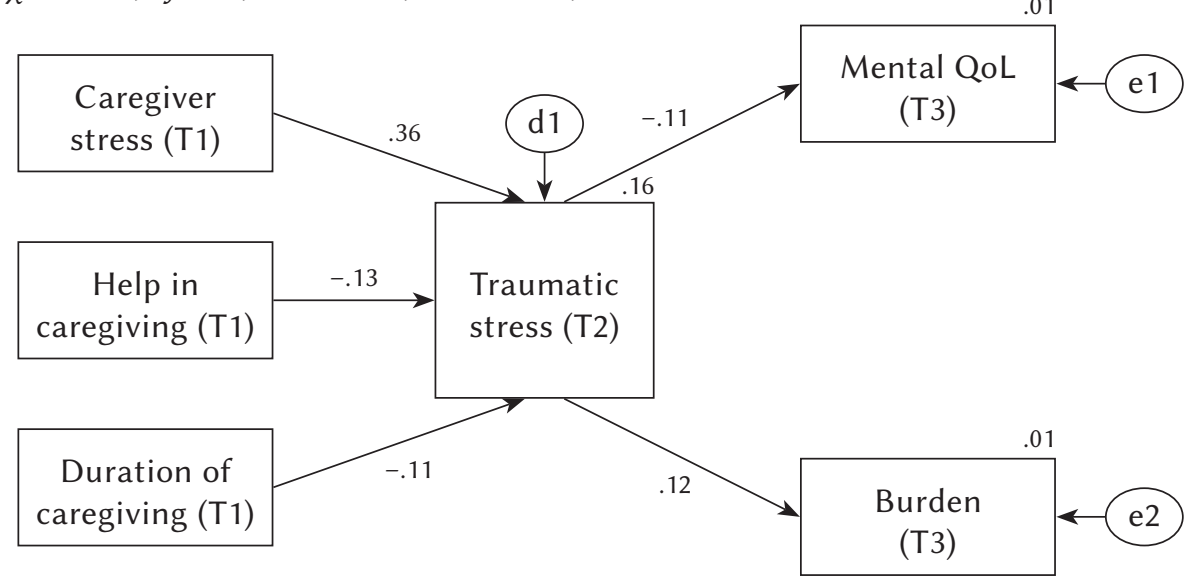


Table 3

Path analysis: Indirect effects

\begin{tabular}{lccrcc}
\hline $\begin{array}{l}\text { Independent } \\
\text { variable }\end{array}$ & $\begin{array}{c}\text { Mediator } \\
\text { variable }\end{array}$ & $\begin{array}{c}\text { Dependent } \\
\text { variable }\end{array}$ & $\begin{array}{c}\text { B mean } \\
\text { indirect } \\
\text { effect }\end{array}$ & $\begin{array}{c}\text { SE of } \\
\text { mean }\end{array}$ & $p$ \\
\hline Caregiver stress (T1) & Traumatic stress (T2) & Mental QoL (T3) & -.04 & .04 & $<.001$ \\
Duration of caregiving (T1) & Traumatic stress (T2) & Mental QoL (T3) & .01 & .02 & $<.001$ \\
Help in caregiving (T1) & Traumatic stress (T2) & Mental QoL (T3) & .01 & .02 & $<.001$ \\
Caregiver stress (T1) & Traumatic stress (T2) & Burden (T3) & .00 & .04 & $<.001$ \\
Duration of caregiving (T1) & Traumatic stress (T2) & Burden (T3) & -.02 & .02 & $<.001$ \\
Help in caregiving (T1) & Traumatic stress (T2) & Burden (T3) & -.01 & .02 & $<.001$ \\
\hline
\end{tabular}

ter educated caregivers had lower odds of feeling physically burdened by caregiving. Social support both at T1 and T2 correlated negatively with traumatic stress at T2. This result is in line with Lage (2005) and Pan et al. (2019), who reported that social support decreases the negative consequences of caregiving, buffering the effect of stress on health. Caregiver stress at T1 and T2 correlated positively with traumatic stress at T2; in fact, caregivers caring for patients experiencing acute traumatic events (such as amputation surgery) often develop traumatic stress as a result (Solorzano et al., 2019), leading to a reduction of quality of life (Ganjparvar et al., 2016), which explains the results in which caregiver stress was negatively associated with physical and mental QoL.

According to the results, throughout the three assessment moments, physical QoL and mental QoL did not significantly change, which is corroborated by Pucciarelli and colleagues (2018), who found that caregiver quality of life did not change significantly over 12 months. Also, Götze et al. (2018) stated that there were no changes in quality of life over time in caregivers.

Burden decreased over time. Pucciarelli and colleagues (2018), in a study regarding quality of life, anxiety, depression and burden among stroke caregivers, stated that burden in caregivers decreased from baseline to 3 months, then increased up to 9 months. Lee and colleagues (2018) also found different types of trajectories of the caregiver burden (high, moderate and low burden), in which the great majority of caregivers presented a moderate burden. But Potier and colleagues (2018) stated that caregiver experiences, assessed with the Zarit Burden Interview, were relatively stable over 16 months. According to Oldenkamp (2018), primary stressors (e.g., deteriorating health situation of the care recipient; characteristics of the informal care) and secondary stressors (e.g., the contamination of other areas of life) were related to negative caregiving experiences such as subjective caregiver burden.

Although burden decreased over time, traumatic stress, caregiver stress and social support did not decrease. Caregiving for patients experiencing acute traumatic events (such as amputation surgery) often falls upon the caregiver (Solorzano et al., 2019) and, in fact, greater anxiety in caregivers 1 month before patients' surgery was associated with higher cortisol output at 2-month follow-up after patients' surgery (Solorzano et al., 2019). Also, Aravena et al. (2018) found perceived change over a 1-month period in daily caregiver concerns and experiences, which may explain the changes in burden.

Duration of caregiving, help in caregiving and caregiver stress at $\mathrm{T} 1$ predicted traumatic stress seven months after patients' amputation (T2); and traumatic stress predicted mental QoL and burden at 10 months (T3). Duration of caregiving has been associated with caregiver burden (Piran et al., 2017) and QoL (Gray et al., 2019). Also, help in caregiving has been associated with burden (Tough et al., 2017) and quality of life (Ribé et al., 2018). Kang and colleagues (2019) found a relationship between caregiver stress and QoL and Wingrove and Rickwood (2019) found that caregiver stress and burden were strongly related. Wintermann and colleagues (2019) found that post-traumatic stress symptoms have an impact on QoL and Young-Hyman et al. (2016) found that post-traumatic stress symptoms had an impact on burden.

In this study, traumatic stress did not mediate the relationship between social support and QoL/ burden. These results may be explained by the sample's sociodemographic characteristics. In fact, the sample includes mostly women with six or less years of education, unemployed or retired (and therefore more available), and married or living in cohabitation (providing care without having to leave home) with limited social support. Since receiving help in 
caregiving tasks was significant, one may assume the importance of this variable over social support. Further studies should test this hypothesis.

Traumatic stress did not mediate the relationship between caregiver stress and physical QoL (only mental QoL). This result is interesting and emphasizes the importance of mental health in caregivers. In fact, Anaforoğlu et al. (2012) found that caregivers of diabetes type 2 patients were more prone to depression and that caregivers report significant levels of burden connected with patient's disability. Further studies should assess the mediator role of traumatic stress on caregiver's QoL, controlling for patient's functional status (Settineri et al., 2014).

This study goes beyond the literature by showing the mediating role of traumatic stress in the relationship between duration of caregiving, caregiving help and caregiver stress on one hand, and mental QoL and burden on the other. Traumatic stress is characterized by the persistence of intense reactions to reminders of a traumatic event, altered mood, a sense of imminent threat, disturbed sleep and hypervigilance (Shalev et al., 2017). Bremner et al. (1999) suggested two subtypes of traumatic stress responses: (1) intrusive memories and hyperarousal and (2) dissociative. In this case, the traumatic event is the amputation, and it seems to be the trigger of the caregiver's traumatic stress, six months later, which mediates the relationship between caregiving characteristics and the associated stress and burden/mental QoL ten months later.

The characteristics of the amputee caregiver sample did not change significantly over time, although the sample size decreased; also, physical QoL and mental QoL did not significantly change over time; burden decreased; however, traumatic stress mediated the significant impact of caregiver stress, duration of caregiving and social support in burden and mental QoL. The set of results seems to suggest that caregivers are able to react to the situation (reduction of burden), but the characteristics of the traumatic event (amputation) and the characteristics of caregiving, by themselves, affect mental quality of life and burden through the traumatic nature of what happens to the patient.

This study has some limitations such as the size of the sample, which requires caution when generalizing results, and the exclusive use of self-reported measures. Future studies should include a bigger sample size and a longer time frame. Finally, the impact of caring on the caregiver's family should also be studied.

The results show the need to design psychological intervention programs for caregivers of amputated patients, which take into consideration the duration of caregiving, the help in caregiving and the caregiver stress, specially one month after patients' amputation, in order to improve mental QoL and decrease burden later on. Therefore, caregivers should be screened for stress during the first month of the patient's amputation and, particularly, those with no help in caregiving and a longer duration of care (started before the patient's amputation) should be offered an intervention to help handle caregiver stress. Nurses dealing with these patients and caregivers should pay attention to the optimal time to provide more information and help to these caregivers.

\section{CONCLUSIONS}

To our knowledge, this study is the first to explore the mediating role of traumatic stress (T2) in the relationship between caregiver's stress, social support, help in caregiving, duration of caregiving at T1 and burden/QoL (T3). However, social support at T1 did not predict traumatic stress at $\mathrm{T} 2$ and, in the final model, none of the variables at $\mathrm{T} 1$ predicted physical QoL at T3. Duration of caregiving, help in caregiving and caregiver stress at $\mathrm{T} 1$ predicted traumatic stress seven months after patients' amputation (T2); and traumatic stress predicted mental QoL and burden at 10 months (T3). These results suggest the importance of caring for the caregiver's mental QoL, emphasizing the need to design mental health interventions, to address traumatic stress triggered by the patient's amputation, in the caregiver population.

Future longitudinal studies should address the role of traumatic stress in caregiver's QoL, taking into consideration the patient's functional status and also include caregivers with higher education.

\section{ACKNOWLEDGMENTS}

This work was supported by a scholarship from the Coordination Foundation for the Improvement of Higher Education Personnel/Full Doctoral Program Abroad Financed by CAPES - Brazil (reference number 1010-14).

\section{DATA AVAILABILITY STATEMENT}

The data that support the findings of this study are available from the corresponding author upon reasonable request.

\section{References}

Anaforoğlu, ì., Ramazanoğulları, ì., Algün, E., \& Kutanis, R. (2012). Depression, anxiety and quality of life of family caregivers of patients with type 2 diabetes. Medical Principles and Practice, 21, 360-365. https://doi.org/10.1159/000334622
Informal caregivers of amputees due to diabetic foot 
Aravena, J. M., Albala, C., \& Gitlin, L. N. (2018). Measuring change in perceived well-being of family caregivers: Validation of the Spanish version of the Perceived Change Index (PCI-S) in Chilean dementia caregivers. International Journal of Geriatric Psychiatry, 33, e120-e130. https:// doi.org/10.1002/gps.4734

Bandeira, M., \& Barroso, S. M. (2005). Sobrecarga das famílias de pacientes psiquiátricos [Family burden of psychiatric patients]. Jornal Brasileiro de Psiquiatria, 54, 34-46.

Suelly Costa,

Joana Ferreira,

Ângela Leite,

M. Graça Pereira

Barrios, P. G., González, R. P., Hanna, S. M., Lunde, A. M., Fields, J. A., Locke, D. E., \& Smith, G. E. (2016). Priority of treatment outcomes for caregivers and patients with mild cognitive impairment: Preliminary analyses. Neurology and Therapy, 5, 183-192. https://doi.org/10.1007/s40120-016-0049-1

Bevans, M., \& Sternberg, E. M. (2012). Caregiving burden, stress, and health effects among family caregivers of adult cancer patients. JAMA, 307, 398-403. https://doi.org/10.1001/jama.2012.29

Boscarino, J. A. (2000). Postwar experiences of Vietnam veterans. In G. Fink (Ed.), Encyclopedia of stress (Vol. 3, pp. 656-662). Academic Press.

Boscarino, J. A. (2004). Posttraumatic stress disorder and physical illness: Results from clinical and epidemiologic studies. Annals of the New York Academy of Sciences, 1032, 141-153. https:// doi.org/10.1196/annals.1314.011

Bremner, J. D., Staib, L. H., Kaloupek, D., Southwick, S. M., Soufer, R., \& Charney, D. S. (1999). Neural correlates of exposure to traumatic pictures and sound in Vietnam combat veterans with and without posttraumatic stress disorder: a positron emission tomography study. Biological Psychiatry, 45, 806-816. https:// doi.org/10.1016/s0006-3223(98)00297-2

Burgio, L., Gaugler, J., \& Hilgeman, M. (Eds.) (2016). The spectrum of family caregiving for adults and elders with chronic illness. Oxford University Press.

Chang, H. Y., Chiou, C. J., \& Chen, N. S. (2010). Impact of mental health and caregiver burden on family caregivers' physical health. Archives of Gerontology and Geriatrics, 50, 267-271. https:// doi.org/10.1016/j.archger.2009.04.006

Costa, M. S. A., Machado, J. C., \& Pereira, M. G. (2018). Burden changes in caregivers of patients with type 2 diabetes: a longitudinal study. Journal of Advanced Nursing, 74, 2322-2330. https:// doi.org/10.1111/jan.13728

Coutrim, H., Azeredo, Z., \& Pereira, M. G. (2007). Impacto do cancro colorectal no doente e cuidadores/família: Implicações para o cuidar [Impact of colorectal cancer on patients and caregivers/family: Implications for caring] (PhD thesis). University of Porto, Porto, Portugal.

Da Silva, F. M., Batista, E. C., \& Cerqueira, G. R. (2017). O uso de fármacos ansiolíticos e antidepressivos pelo cuidador de idoso acamado [The anxiolytics and antidepressants drug use of the elderly caregiver of bedridden]. Saúde em Foco, 3, 62-76.

Day, M. C., Wadey, R., \& Strike, S. (2019). Living with limb loss: Everyday experiences of "good" and "bad" days in people with lower limb amputation. Disability and Rehabilitation, 41, 2433-2442. https://doi.org/10.1080/09638288.2018.1467502

Epstein-Lubow, G., Gaudiano, B. A., Hinckley, M., Salloway, S., \& Miller, I. W. (2010). Evidence for the validity of the American Medical Association's caregiver self-assessment questionnaire as a screening measure for depression. Journal of the American Geriatrics Society, 58, 387-388. https:// doi.org/10.1111/j.1532-5415.2009.02701.x

Epstein, N. B., Baldwin, L. M., \& Bishop, D. S. (1983). The McMaster Family Assessment Device. Journal of Marital and Family Therapy, 9, 171-180. https:// doi.org/10.1111/j.1752-0606.1983.tb01497.x

Ferreira, P. L. (2000). Criação da versão portuguesa do MOS SF-36. Parte I - Adaptação cultural e linguística [Development of the Portuguese version of MOS SF-36. Part I. Cultural and linguistic adaptation]. Acta Médica Portuguesa, 13, 55-66.

Foss, M. H., Martins, M. R., Mazaro, L. M., Martins, M. I., \& Godoy, J. M. (2009). Qualidade de vida dos cuidadores de amputados de membros inferiores [Quality of life of lower limb amputees' caregivers]. Revista Neurociências, 17, 8-13. https://doi.org/10.34024/rnc.2009.v17.8597

Franchini, M. G., \& Savoia, M. G. (2018). Psicoterapia de grupo para pacientes diabéticos amputados e seus cuidadores [Group psychotherapy of diabetes patients with amputations and their caretakers]. Arquivos Médicos dos Hospitais e da Faculdade de Ciências Médicas da Santa Casa de São Paulo, $58,10-17$.

Ganjparvar, Z., Mousavi, B., Masumi, M., Soroush, M., \& Montazeri, A. (2016). Determinants of quality of life in the caregivers of Iranian war survivors with bilateral lower-limb amputation after more than two decades. Iranian Journal of Medical Sciences, 41, 257-264.

Golden-Kreutz, D. M., Thornton, L. M., Gregorio, W. D., Frierson, G. M., Jim, H. S., Carpenter, K. M., Shelby, R. A., \& Andersen, B. L. (2005). Traumatic stress perceived global stress, and life events: prospectively predicting quality of life in breast cancer patients. Health Psychology, 24, 288-296. https:// doi.org/10.1037/0278-6133.24.3.288

Götze, H., Brähler, E., Gansera, L., Schnabel, A., Gottschalk-Fleischer, A., \& Köhler, N. (2018). Anxiety, depression and quality of life in family caregivers of palliative cancer patients during home care and after the patient's death. European Journal of Cancer Care, 27, e12606. https://doi.org/10.1111/ecc.12606

Gray, N. A., Zuo, L., Hong, D., Smyth, B., Jun, M., De Zoysa, J., Vo, K., Howard, K., Wang, J., Lu, C., 
\& Liu, Z. (2019). Quality of life in caregivers compared with dialysis recipients: The Co-ACTIVE sub-study of the ACTIVE dialysis trial. Nephrology, 24, 1056-1063. https://doi.org/10.1111/nep.13530

Kang, A., Yu, Z., Foo, M., Chan, C. M., \& Griva, K. (2019). Evaluating burden and quality of life among caregivers of patients receiving peritoneal dialysis. Peritoneal Dialysis International, 39, 176180. https://doi.org/10.3747/pdi.2018.00049

Kaux, J. F., Delvaux, F., Schaus, J., Demoulin, C., Locquet, M., Buckinx, F., Beaudart, C., Dardenne, N., Van Beveren, J., Croisier, J. L., Forthomme, B., \& Bruyère, O. (2016). Cross-cultural adaptation and validation of the Patient-Rated Tennis Elbow Evaluation Questionnaire on lateral elbow tendinopathy for French-speaking patients. Journal of Hand Therapy, 29, 496-504. https://doi.org/10.1016/j.jht.2016.06.007

Lage, M. I. (2005). Cuidados familiares a idosos [Family care for the elderly]. In C. Paul \& A. M. Fonseca (Eds.), Envelhecer em Portugal [Getting older in Portugal] (pp. 203-229). Climepsi Editores.

Lee, Y. H., Liao, Y. C., Shun, S. C., Lin, K. C., Liao, W. Y., Chang, P. H., Jhang, S. Y., Yu, C. J., Yang, P. C., Hsieh, P. Y., \& Lai, Y. H. (2018). Trajectories of caregiver burden and related factors in family caregivers of patients with lung cancer. Psycho-Oncology, 27, 1493-1500. https://doi.org/10.1002/pon.4678

Mason, J. E., LeBouthillier, D. M., \& Asmundson, G. J. (2019). Relationships between health behaviors, posttraumatic stress disorder, and comorbid general anxiety and depression. Cognitive Behaviour Therapy, 48, 184-199. https:// doi.org/10.1080/16506073.2018.1498119

Nazarko, L. (2019). Diabetes and foot problems: The role of the practice nurse. Practice Nursing, 30, 9-15. https://doi.org/10.12968/pnur.2019.30.1.9

Oldenkamp, M. (2018). Caregiving experiences of informal caregivers: The importance of characteristics of the informal caregiver, care recipient, and care situation. Rijksuniversiteit Groningen.

Pan, K. C., Hung, S. Y., Chen, C. I., Lu, C. Y., Shih, M. L., \& Huang, C. Y. (2019). Social support as a mediator between sleep disturbances, depressive symptoms, and health-related quality of life in patients undergoing hemodialysis. PLoS One, 14, e0216045. https://doi.org/10.1371/journal.pone.0216045

Pedras, S., Carvalho, R., \& Pereira, M. G. (2018). Predictors of quality of life in patients with diabetic foot ulcer: The role of anxiety, depression, and functionality. Journal of Health Psychology, 23, 14881498. https://doi.org/10.1177/1359105316656769

Pedras, S., Carvalho, R., \& Pereira, M. G. (2016). Quality of life in Portuguese patients with diabetic foot ulcer before and after an amputation surgery. International Journal of Behavioral Medicine, 23, 714721. https://doi.org/10.1007/s12529-016-9567-6

Pedras, S., Preto, I., Carvalho, R., \& Pereira, M. G. (2019). Traumatic stress symptoms following a lower limb amputation in diabetic patients: a longitudinal study. Psychology \& Health, 34, 535-549. https://doi.org/10.1080/08870446.2018.1545907

Pedras, S., Vilhena, E., Carvalho, R., \& Pereira, M. G. (2018). Psychosocial adjustment to a lower limb amputation ten months after surgery. Rehabilitation Psychology, 63, 418-430. https:// doi.org/10.1037/rep0000189

Pereira, M. G., \& Costa, S. (2013a). Versão do Revised Impact of Events Scale para cuidadores de pacientes diabetticos mellitus tipo 2 amputados devido pé diabético [Version of the Revised Impact of Events Scale for caregivers of type 2 diabetic mellitus patients amputated due to diabetic foot]. Family Health \& Disease Research Group, School of Psychology, University of Minho, Braga, Portugal. Pereira, M. G., \& Costa, S. (2013b). Versão do Self-Assessment Caregiver Questionnaire para cuidadores de pacientes diabéticos mellitus tipo 2 amputados devido pé diabético [Version of the Self-Assessment Caregiver Questionnaire for caregivers of type 2 diabetic mellitus patients amputated due to diabetic foot]. Family Health \& Disease Research Group, School of Psychology, University of Minho, Braga, Portugal.

Piran, P., Khademi, Z., Tayari, N., \& Mansouri, N. (2017). Caregiving burden of children with chronic diseases. Electronic Physician, 9, 5380. https:// doi.org/10.19082/5380

Potier, F., Degryse, J. M., Bihin, B., Debacq-Chainiaux, F., Charlet-Renard, C., Martens, H., \& de Saint-Hubert, M. (2018). Health and frailty among older spousal caregivers: an observational cohort study in Belgium. BMC Geriatrics, 18, 291. https:// doi.org/10.1186/s12877-018-0980-3

Pucciarelli, G., Ausili, D., Galbussera, A. A., Rebora, P., Savini, S., Simeone, S., Alvaro, R., \& Vellone, E. (2018). Quality of life, anxiety, depression and burden among stroke caregivers: a longitudinal, observational multicentre study. Journal of Advanced Nursing, 74, 1875-1887. https:// doi.org/10.1111/jan.13695

Reinhard, S. C., Gubman, G. D., Horwitz, A. V., \& Minsky, S. (1994). Burden assessment scale for families of the seriously mentally ill. Evaluation and Program Planning, 17, 261-269. https:// doi.org/10.1016/0149-7189(94)90004-3

Ribé, J. M., Salamero, M., Pérez-Testor, C., Mercadal, J., Aguilera, C., \& Cleris, M. (2018). Quality of life in family caregivers of schizophrenia patients in Spain: Caregiver characteristics, caregiving burden, family functioning, and social and professional support. International Journal of Psychiatry In Clinical Practice, 22, 25-33. https:// doi.org/10.1080/13651501.2017.1360500.4

Ribeiro, J. L. P. (1999). Escala de Satisfação com o Suporte Social (ESSS) [Social Support Satisfaction Scale (SSSS)]. Análise Psicológica, 17, 547-558.
Informal caregivers of amputees due to diabetic foot 
Suelly Costa,

Joana Ferreira,

Ângela Leite,

M. Graça Pereira
Ryu, J. H., Kredentser, M. S., Bienvenu, O. J., Blouw, M., Sareen, J., \& Olafson, K. (2016). Post-traumatic stress disorder in survivors of critical illness. In C. Martin, V. Preedy, \& V. Patel (Eds.), Comprehensive guide to post-traumatic stress disorders (pp. 263-280). Springer.

Settineri, S., Rizzo, A., Liotta, M., \& Mento, C. (2014). Caregiver's burden and quality of life: Caring for physical and mental illness. International Journal of Psychological Research, 7, 30-39. https:// doi.org/10.21500/20112084.665

Shalev, A., Liberzon, I., \& Marmar, C. (2017). Post-traumatic stress disorder. New England Journal of Medicine, 376, 2459-2469. https:// doi.org/10.1056/NEJMra1612499

Schnitzer, S., Oedekoven, M., Amin-Kotb, K., Gellert, P., Balke, K., \& Kuhlmey, A. (2017). Caregivers' burden and education level: Does subjective health mediate the association? Innovation in Aging, 1, 447. https://doi.org/10.1093/geroni/igx004.1599

Solorzano, C. S., Steptoe, A., Leigh, E., Kidd, T., Jahangiri, M., \& Poole, L. (2019). Pre-surgical caregiver burden and anxiety are associated with post-surgery cortisol over the day in caregivers of coronary artery bypass graft surgery patients. International Journal of Behavioral Medicine, 26, 316-322. https://doi.org/10.1007/s12529-019-09775-6

Tochel, C., Smith, M., Baldwin, H., Gustavsson, A., Ly, A., Bexelius, C., Nelson, M., Bintener, C., Fantoni, E., Garre-Olmo, J., Janssen, O., Jindra, C., Jørgensen, I. F., McKeown, A., Öztürk, B., Ponjoan, A., Potashman, M. H., Reed, C., Roncancio-Diaz, E., Vos, S., Sudlow, C., \& ROADMAP consortium (2019). What outcomes are important to patients with mild cognitive impairment or Alzheimer's disease, their caregivers, and health-care professionals? A systematic review. Alzheimer's \& Dementia, 11, 231-247. https:// doi.org/10.1016/j.dadm.2018.12.003

Tough, H., Brinkhof, M. W., Siegrist, J., \& Fekete, C. (2017). Subjective caregiver burden and caregiver satisfaction: the role of partner relationship quality and reciprocity. Archives of Physical Medicine and Rehabilitation, 98, 2042-2051. https:// doi.org/10.1016/j.apmr.2017.02.009

Valeberg, B. T., \& Grov, E. K. (2013). Symptoms in the cancer patient - Of importance for their caregivers' quality of life and mental health? European Journal of Oncology Nursing, 17, 46-51. https:// doi.org/10.1016/j.ejon.2012.01.009

Vranceanu, A. M. (2019). Can we prevent chronic posttraumatic stress disorder in caregivers of critical care patients? Journal of Emergency and Critical Care Medicine, 3, 2. https:// doi.org/10.21037/jeccm.2019.01.02

Ware, J. E. Jr, Kosinski, M., Gandek, B., Aaronson, N. K., Apolone, G., Bech, P., Brazier, J., Bullinger, M., Kaasa, S., Leplège, A., \& Prieto, L. (1998). The factor structure of the SF-36 Health Survey in 10 countries: Results from the IQOLA Project. Journal of Clinical Epidemiology, 51, 1159-1165. https://doi.org/10.1016/S0895-4356(98)00107-3

Weiss, D. S., \& Marmar, C. R. (1997). The Impact of Event Scale-Revised. In J. P. Wilson \& T. M. Keane (Eds.), Assessing psychological trauma and PTSD: a practitioner's handbook (pp. 399-411). Guilford Press.

Wingrove, C., \& Rickwood, D. (2019). Parents and carers of young people with mental ill-health: What factors mediate the effect of burden on stress? Counselling Psychology Quarterly, 32, 121-134. https://doi.org/10.1080/09515070.2017.1384362

Wintermann, G. B., Petrowski, K., Weidner, K., Strauß, B., \& Rosendahl, J. (2019). Impact of post-traumatic stress symptoms on the healthrelated quality of life in a cohort study with chronically critically ill patients and their partners: Age matters. Critical Care, 23, 39. https:// doi.org/10.1186/s13054-019-2321-0

Young-Hyman, D., De Groot, M., Hill-Briggs, F., Gonzalez, J. S., Hood, K., \& Peyrot, M. (2016). Psychosocial care for people with diabetes: a position statement of the American Diabetes Association. Diabetes Care, 39, 2126-2140. https:// doi.org/10.2337/dc16-2053 